\title{
Europace
}

\section{Time-to-First Appropriate Shock in Patients Implanted Prophylactically with an Implantable Cardioverter Defibrillator: \\ Data from the Survey on Arrhythmic Events in BRUgada Syndrome (SABRUS) \\ --Manuscript Draft--}

Manuscript Number:

Full Title:

Article Type:

Keywords:

Corresponding Author:

Corresponding Author Secondary

Information:

Corresponding Author's Institution:

Corresponding Author's Secondary Institution:

First Author:

First Author Secondary Information:

Order of Authors:
EUPC-D-18-01041R1

Time-to-First Appropriate Shock in Patients Implanted Prophylactically with an Implantable Cardioverter Defibrillator:

Data from the Survey on Arrhythmic Events in BRUgada Syndrome (SABRUS)

Clinical Research

Brugada syndrome; ICD; appropriate therapy; arrhythmic event

Anat Milman, MD PhD

Tel Aviv Sourasky Medical Center

Tel Aviv, ISRAEL

Tel Aviv Sourasky Medical Center

Tel Aviv University Sackler Faculty of Medicine

Anat Milman, MD PhD

Anat Milman, MD PhD

Aviram Hochstadt, MD

Antoine Andorin, MD

Jean-Baptiste Gourraud, MD, PhD

Frederic Sacher, MD

Philippe Mabo, MD

Sung-Hwan Kim, MD

Giulio Conte, MD, PhD

Elena Arbelo, MD, PhD

Tsukasa Kamakura, MD, PhD

Takeshi Aiba, MD, PhD

Carlo Napolitano, MD, PhD

Carla Giustetto, MD

Isabelle Denjoy, MD

Jimmy JM Juang, MD, PhD

Shingo Maeda, MD, PhD

Yoshihide Takahashi, MD, PhD

Eran Leshem, MD

Yoav Michowitz, MD

Michael Rahkovich, MD

Camilla $\mathrm{H}$. Jespersen, MD 
Yanushi D. Wijeyeratne, MD

Jean Champagne, MD

Leonardo Calo, MD

Zhengrong Huang, MD, PhD

Yuka Mizusawa, MD

Pieter G. Postema, MD, PhD

Ramon Brugada, MD, PhD

Arthur A.M. Wilde, MD, PhD

Gan-Xin Yan, MD, PhD

Elijah R. Behr, MD

Jacob Tfelt-Hansen, MD, DMSc

Kenzo Hirao, MD, PhD

Christian Veltmann, MD

Antoine Leenhardt, MD

Domenico Corrado, MD, PhD

Fiorenzo Gaita, MD

Silvia G. Priori, MD, PhD

Kengo F. Kusano, MD, PhD

Masahiko Takagi, MD, PhD

Pietro Delise, MD

Josep Brugada, MD, PhD

Pedro Brugada, MD, PhD

Gi-Byoung Nam, MD, PhD

Vincent Probst, MD, PhD

Bernard Belhassen, MD

Order of Authors Secondary Information:

Abstract:

Aims.

Data on predictors of time-to-first appropriate ICD therapy in patients with Brugada syndrome (BrS) and prophylactically implanted ICD's are scarce.

Methods.

SABRUS is an international survey on $678 \mathrm{BrS}$-patients who experienced arrhythmic event $(A E)$ including 252 patients in whom $A E$ occurred after prophylactic ICD implantation. Analysis was performed on time-to-first appropriate ICD discharge regarding patients' characteristics. Multivariate logistic regression models were utilized to identify which parameters predicted time to arrhythmia $\leq 5$ years.

Results.

The median time-to-first appropriate ICD therapy was $24.8 \pm 2.8$ months. A shorter time was observed in patients from Asian ethnicity $(p<0.05)$, those with syncope $(p=0.001)$ and those with class Ila indication for ICD $(p=0.001)$. A longer time was associated with a positive family history of sudden cardiac death $(p<0.05)$. Multivariate Cox regression revealed shorter time-to-ICD therapy in patients with syncope (OR 1.65, $P=0.001)$. In 193 patients $(76.6 \%)$, therapy was delivered during the first 5 years. Factors associated with this time were syncope (OR 0.36, $p=0.001)$, spontaneous type 1 Brugada ECG (OR 0.5, p<0.05) and class Ila indication (OR 0.38, p<0.01) as opposed to class IIb (OR 2.41, $p<0.01$ ). A near-significant trend for female gender was also noted (OR $0.13, p=0.052$ ). Two score models for prediction of $<5$ years to shock were built.

Conclusions. 
First appropriate therapy in BrS-patients with prophylactic ICD's occurred during the first 5 years in $76.6 \%$ of patients. Syncope and spontaneous type 1 Brugada-ECG correlated with a shorter time to ICD therapy. 


\section{'What's New?'}

1. In patients with $\mathrm{BrS}$ who had an appropriate shock from a prophylactically implanted $I C D$, the great majority (76.6\%) received this shock during the first 5 years after ICD implantation.

2. Clinical parameters predicting a shorter time to appropriate shock were syncope and a spontaneous type 1 ECG. A near-significant trend for female gender was also noted.

3. Two score models were built using these parameters to predict the time to first $A E$ and will need to be validated in future studies. 


\section{ABSTRACT}

\section{Aims.}

Data on predictors of time-to-first appropriate ICD therapy in patients with Brugada syndrome (BrS) and prophylactically implanted ICD's are scarce.

\section{Methods.}

SABRUS is an international survey on $678 \mathrm{BrS}$-patients who experienced arrhythmic event (AE) including 252 patients in whom AE occurred after prophylactic ICD implantation. Analysis was performed on time-to-first appropriate ICD discharge regarding patients' characteristics. Multivariate logistic regression models were utilized to identify which parameters predicted time to arrhythmia $\leq 5$ years.

\section{Results.}

The median time-to-first appropriate ICD therapy was $24.8 \pm 2.8$ months. A shorter time was observed in patients from Asian ethnicity $(p<0.05)$, those with syncope $(p=0.001)$ and those with class Ila indication for ICD ( $p=0.001)$. A longer time was associated with a positive family history of sudden cardiac death $(p<0.05)$. Multivariate Cox regression revealed shorter time-to-ICD therapy in patients with syncope (OR 1.65, P=0.001). In 193 patients (76.6\%), therapy was delivered during the first 5 years. Factors associated with this time were syncope (OR 0.36, $p=0.001)$, spontaneous type 1 Brugada ECG $(O R 0.5, p<0.05)$ and class Ila indication (OR 0.38, $p<0.01$ ) as opposed to class IIb (OR 2.41, $p<0.01$ ). A nearsignificant trend for female gender was also noted (OR 0.13, $p=0.052$ ). Two score models for prediction of $<5$ years to shock were built.

\section{Conclusions.}

First appropriate therapy in BrS-patients with prophylactic ICD's occurred during the first 5 
years in $76.6 \%$ of patients. Syncope and spontaneous type 1 Brugada-ECG correlated with a shorter time to ICD therapy.

Key Words: Brugada Syndrome, ICD, appropriate therapy, arrhythmic event 


\section{Condensed abstract.}

SABRUS collected 252 patients in whom AE occurred after prophylactic ICD implantation.

First appropriate ICD therapy occurred during first 5 years in $76.6 \%$ of patients. Syncope and spontaneous type 1 Brugada-ECG (comprising class Ila indication for prophylactic ICD

implantation) correlated with shorter time to ICD therapy. 
November 13, 2018

Professor Gerhard Hindricks

Editor-in-Chief

EUROPACE

Dear Professor Gerhard Hindricks

Enclosed please find our revised manuscript entitled: "Time-to-First Appropriate Shock in Patients Implanted Prophylactically with an Implantable Cardioverter Defibrillator: Data from the Survey on Arrhythmic Events in BRUgada Syndrome (SABRUS)" by Dr Anat Milman and coworkers.

We have carefully read all reviewers comments and made all necessary changes which helped in improving the manuscript. We attached for your convenience the revised manuscript with all changes marked in yellow in order to facilitate their tracking here in this letter.

We hope that you will find it suitable for publication in EUROPACE.

Sincerely yours,

Anat Milman, MD PhD

On behalf of the SABRUS co-authors 


\begin{abstract}
Aims.

Data on predictors of time-to-first appropriate ICD therapy in patients with Brugada syndrome (BrS) and prophylactically implanted ICD's are scarce.
\end{abstract}

Methods.

SABRUS is an international survey on $678 \mathrm{BrS}$-patients who experienced arrhythmic event (AE) including 252 patients in whom AE occurred after prophylactic ICD implantation. Analysis was performed on time-to-first appropriate ICD discharge regarding patients' characteristics. Multivariate logistic regression models were utilized to identify which parameters predicted time to arrhythmia $\leq 5$ years.

\title{
Results.
}

The median time-to-first appropriate ICD therapy was $24.8 \pm 2.8$ months. A shorter time was observed in patients from Asian ethnicity $(p<0.05)$, those with syncope $(p=0.001)$ and those with class Ila indication for ICD $(p=0.001)$. A longer time was associated with a positive family history of sudden cardiac death $(p<0.05)$. Multivariate Cox regression revealed shorter time-to-ICD therapy in patients with syncope (OR 1.65, $\mathrm{P}=0.001$ ). In 193 patients (76.6\%), therapy was delivered during the first 5 years. Factors associated with this time were syncope (OR 0.36, $p=0.001$ ), spontaneous type 1 Brugada ECG (OR 0.5, $p<0.05)$ and class Ila indication (OR 0.38, $\mathrm{p}<0.01$ ) as opposed to class IIb (OR 2.41, $\mathrm{p}<0.01$ ). A nearsignificant trend for female gender was also noted (OR $0.13, p=0.052$ ). Two score models for prediction of $<5$ years to shock were built.

\section{Conclusions.}

First appropriate therapy in BrS-patients with prophylactic ICD's occurred during the first 5 years in $76.6 \%$ of patients. Syncope and spontaneous type 1 Brugada-ECG correlated with a shorter time to ICD therapy.

Key Words: Brugada Syndrome, ICD, appropriate therapy, arrhythmic event 
Condensed abstract.

SABRUS collected 252 patients in whom AE occurred after prophylactic ICD implantation. First appropriate ICD therapy occurred during first 5 years in $76.6 \%$ of patients. Syncope and spontaneous type 1 Brugada-ECG (comprising class Ila indication for prophylactic ICD implantation) correlated with shorter time to ICD therapy. 


\section{'What's New?'}

1. In patients with $\mathrm{BrS}$ who had an appropriate shock from a prophylactically implanted $I C D$, the great majority (76.6\%) received this shock during the first 5 years after ICD implantation.

2. Clinical parameters predicting a shorter time to appropriate shock were syncope and a spontaneous type 1 ECG. A near-significant trend for female gender was also noted.

3. Two score models were built using these parameters to predict the time to first $A E$ and will need to be validated in future studies. 


\section{INTRODUCTION}

Brugada syndrome (Brs) is a well-recognized cause of sudden cardiac death (SCD) particularly in apparently healthy middle-aged males(1). The cause of death is a ventricular tachyarrhythmia usually occurring without precipitating warning signs(2). Most clinical research on this potentially lethal arrhythmic disease has mainly focused on risk stratification to identify patients at risk who will benefit from an implanted cardioverterdefibrillator (ICD), the most advocated option to prevent SCD.

Present indications for prophylactic ICD implantation in patients with BrS-ECG include(3): 1) Spontaneous type 1 Brugada-ECG pattern and a history of syncope (class lla indication); 2) Spontaneous or drug-induced type 1 Brugada-ECG with induction of ventricular fibrillation during programmed ventricular stimulation with 2 or 3 extrastimuli (class Ilb indication). When a patient is identified as complying with these guideline recommendations(3), the most appropriate timing of the implantation is unknown with a double-edged sword decision for implant: too early might expose the patient to possible complications whereas too late might have a detrimental outcome.

SABRUS is a multicenter international survey that collected data on a large cohort $(n=678)$ of BrS-patients who experienced AE including 252 patients in whom the AE occurred after a prophylactic ICD implantation.

The present study sought to gain insight into the factors that affect the time-to-first appropriate ICD therapy in all the $252 \mathrm{BrS}$ patients who received a prophylactic ICD.

\section{METHODS}

Study group. As mentioned in previous papers $(1,2)$, the SABRUS cohort population comprised a total of $678 \mathrm{BrS}$-patients with $\mathrm{AE}$ who were recruited from 23 centers from both 10 Western countries (426 patients; 62.8\%) and 4 Asian countries (252 patients; $37.2 \%$ ). In 426 patients (group A), the AE was documented during aborted CA while in 252 patients (group B) the AE was documented from an ICD implanted prophylactically following conventional class Ila or Ilb indications(3) (75\% of patients) or non-class Ila or Ilb indications (25\% of patients)(2).

Group B patients comprised the study group of the present study.

The study was approved by the Research Ethics Boards of all participating institutions.

\section{DATA ACQUISITION.}

Anonymous patient information was collected using a predefined questionnaire regarding the following: 1) gender; 2) patient age at time of ICD implantation; 3) date of ICD implantation; 4) date at which the first AE occurred after ICD implantation; 4) ethnicity (Caucasian, Asian, other or unknown); 5) proband status; 6) family history of SCD; 7) prior history of syncope ; 8) presence of spontaneous or drug-induced Brugada-ECG type 1;7) inducibility of sustained ventricular fibrillation (VF) at EP study (EPS) and 9) results of genetic testing for the presence of SNC5A mutation.

\section{DEFINITIONS.}

Arrhythmic events: AE was defined as any sustained ventricular tachyarrhythmia triggering appropriate ICD shock therapy.

\section{STATISTICAL ANALYSIS.}


Estimation of median time to AE for ordinal variables was done using Kaplan-Meier curves; significance of the difference between two curves was calculated using the log-rank test. Multivariate time to $\mathrm{AE}$ analysis and analysis of continuous parameters was done using Cox regression models. Calculation of each parameter effect on probability of time to AE being $>5$ years was done using binary logistic regression models. To prevent detection bias due to patients with longer follow up having a longer time to $A E$, we added the year of ICD implantation in all of the multivariate analyses to cancel out this effect. Out of the multivariate logistic regression model we built prediction scores using the relative odd ratios as a guide to each parameter score. The trend between the scores and the above probability was assessed using Mantel-Haenszel test of trend and the highest-ranking scores were selected. Time to $A E$ is shown as Median $\pm \mathrm{SE}$. P-values were considered significant when $\mathrm{P}<0.05$, all calculations were done using SPSS v. 24 from IBM, Armonk, Virginia.

\section{RESULTS}

Study group. The study group comprised 252 patients aged 1.1-77.5 (mean $46.1 \pm 13.3$ ) years at time of $A E$, most being males ( $n=229,91 \%)$ and Caucasians ( $n=160,63.5 \%)$ (Supplemental Table 1). A positive family history of SCD and a prior history of syncope were present in $29 \%$ and $63 \%$ of patients, respectively. A spontaneous type 1 Brugada-ECG was observed in $69 \%$ of patients. Most of the patients (79\%) underwent an EPS during which VF was inducible in $72 \%$ of them. Genetic testing was performed in $67 \%$ of patients and revealed an SCN5A mutation in $36 \%$ of them. The age at time of ICD implantation ranged from 1-73.2 years (mean $43.4 \pm 13.1$ ).

Time-to-shock. The time-to-shock ranged from 0 to 168.4 months (median $24.4 \pm 2.8$ months), Figure 1 shows the Kaplan Meier curves for the entire time span. Table 1 elaborates the comparison of the median time-to-shock according to different patient characteristics and Figure 2 displays the results. The following two factors were found to be associated with a significantly shorter time-to-shock: Asian vs. Caucasian ethnicity $(16.5 \pm 4.8$ vs. $30.9 \pm 16.5$ months respectively, $\mathrm{P}<0.05)$ and a prior history of syncope vs. being asymptomatic ( $19.5 \pm 2.5$ vs. $36.5 \pm 4.9$ months respectively, $\mathrm{P}=0.001)$. In contrast a positive family history of SCD resulted in a longer time-to-shock (33.5 \pm 4.8 vs. $21.2 \pm 3.1$ months in patients without such a history, $\mathrm{P}<0.05)$.

In respect to the conventional indications of prophylactic ICD implantation (3), the shortest median time-to-shock was observed in the class lla subgroup (17.8 \pm 3.5 months) as compared to class IIb subgroup (37.2 \pm 4.2 months, $\mathrm{P}=0.001$ ) or to non $\mathrm{Ila} / \mathrm{Ilb}$ indications (29.6 \pm 2.8 months, $\mathrm{P}=0.058$ )

Univariate Cox regression for continuous variables did not find a significant relation between a shorter time-to-shock and patient age at time of ICD implantation [P=0.285; odds ratio [OR]. 1.06; 95\% confidence interval $(\mathrm{Cl}) .0 .96-1.17]$. Multivariate Cox regression was significant for a history of syncope $[P=0.001$; OR $1.65 ; 95 \% \mathrm{Cl} 1.21-2.25]$ and for year of ICD implantation $[\mathrm{P}<0.001 ; \mathrm{OR} 1.12 ; 95 \% \mathrm{Cl} 1.07-1.16]$ but not for ethnicity or family history of SCD.

Less than 5 years-to-shock time. Table 2 shows patients characteristics in respect to a 5 years-to-shock time. In 193 (76.6\%) patients appropriate ICD shock therapy was delivered during the first 5 years. Univariate logistic regression (Figure 3) analyses showed that factors favoring this time lag were a prior history of syncope $(P=0.001,0 R .0 .36 ; 95 \% \mathrm{Cl} 0.2$ - 
$0.65)$, the presence of a spontaneous type 1 Brugada-ECG ( $P<0.05$, OR. 0.5; 95\% Cl 0.270.92 ) and the year of ICD implantation ( $P<0.001$; OR. 0.87; 95\% Cl 0.82-0.94). Female gender showed a trend towards shock time less than 5 years ( $P=0.052$, OR. 0.13; 95\% Cl 0.02-1.02), Multivariate Cox regression analysis was significant for all the aforementioned parameters (Supplemental Table 3).

Opposite results were found between the class Ila and IIb indications for prophylactic ICD implantation: a class Ila indication was a significant predictor for $\leq 5$ years-to-appropriate shock ( $\mathrm{P}<0.01$; OR. 0.38; 95\% Cl 0.2-0.71) whereas a class Ilb indication was a significant predictor for $>5$ years-to-appropriate shock ( $\mathrm{P}<0.01$; OR. 2.41; 95\% Cl 1.32-4.22) (Figure 3).

Time-to-Shock Score. Taking into consideration the aforementioned patients' characteristics predicting a time-to-shock $\leq 5$ years, their relative odds ratio, and parameter significance, two risks scores were built. One with a history of syncope and spontaneous type 1 Brugada ECG (minimal score) and the second with female gender added, as it had a borderline significance, yet we postulated it could add power to the score (gender augmented score).

These Scores sum the risk factors found to have significance for an earlier AE after a prophylactic ICD implantation. Each risk factor received a score between 1 and 2 and the sum gives the percentage of patients who received an appropriate therapy during the first 5 years from the implant (Figure 4). One point is given for either prior syncope or the presence of a spontaneous type 1 Brugada-ECG, and for the gender augmented score - 2 points were added for female gender. The scores range between 0 and 2 for the minimal score and 0 and 4 for the gender augmented score. A score of 0 was found in $50.0 \%$ of patients using the minimal score and in $46.4 \%$ of patients using the gender augmented score. A maximal score ( 2 in the minimal score system and 4 in the gender augmented system) was observed in $85 \%$ and $100 \%$ of patients, respectively. The trend between the score and the percentage of patients with time to shock less than 5 years was highly significant for both scores ( $p<0.001$ for both) but reached a higher level for the gender augmented score (Mantel-Haenszel statistics of 16 and 20.1 for the minimal and the gender augmented scores, accordingly).

\section{DISCUSSION}

Our study showed that the median time-to-first appropriate ICD therapy in the $252 \mathrm{BrS}$ patients who received a prophylactic ICD was $24.8 \pm 2.8$ months. The shortest times were observed in patients of Asian ethnicity, in those with prior syncope and in those who had a class Ila indication for ICD implantation. The longest time was associated with a positive family history of SCD. In > 3 quarters of the study patients, appropriate ICD therapy was delivered during the first 5 years after implantation, especially in patients with a female gender, those with a prior syncope and those with a spontaneous type 1 Brugada-ECG. Two score models for predicting a time-to-shock $\leq 5$ years were built according to the significance of the parameters; one included syncope and a type 1 Brugada ECG and the second included female gender which had a borderline significance and resulted in a $100 \%$ accuracy when patients exhibited all these characteristics.

\section{Time-to-shock.}

The literature regarding the time-to-first appropriate shock therapy in BrS patients implanted prophylactically with an ICD is scarce. Only 3 studies report their results on small 
patient cohorts (ranging from 7 to 34 patients)(4-6). Sarkozy et al.(5) found a mean time-tofirst appropriate therapy of 13 months ( 3 days to 4 years) in 7 male patients including 3 with a history of syncope. They did not find a significant predictor of appropriate shock-free survival(5). In an earlier study, Sacher et al.(4) demonstrated that the asymptomatic group $(n=5)$ had a shorter median time-to-shock (16 months) than the syncope group $(n=9)(24$ months)(4). However, in a latter larger study by the same group with prolonged follow-up duration, time-to-shock lengthened with no difference found between the symptomatic (47 months, $\mathrm{n}=22$ ) and asymptomatic (45 months, $\mathrm{n}=12$ ) groups(6).

In the present study which involved the largest cohort population with AEs documented after prophylactic ICD implantation ( $n=252$ ), the median time-to-shock was 24.8 months. Asian ethnicity and a history of syncope were predictors of a shorter time-to-shock, suggesting these factors should be taken into consideration when contemplating ICD implantation. This is consistent with the fact that group Ila patients had the shortest timeto-shock.

By multivariate logistic regression the presence of syncope was found to correlate with a shorter time-to-shock (19.5 \pm 2.5 months vs. $36.5 \pm 4.9$ months in asymptomatic patients, $\mathrm{P}<0.001)$. It is noteworthy that these results are in agreement with those of the FINGER study(7) where time-to-first event was reported to be significantly shorter in the syncope group patients than in the asymptomatic group.

In the present study, a positive family history of SCD correlated with a longer time-to-shock, however these findings should be considered with caution since they were seen only in the univariate analysis and not in the multivariate one. One possible explanation could be a biased decision taken by the referring patient's physician who considered a family history of SCD as a major risk factor. On the other hand, we already stressed elsewhere the problematic definition of family history of SCD in our study(2). ICD implant year was a predictor of early $A E$, mostly due to longer follow-up in patients that had an ICD implanted in the past, although this finding might also represent different trends in ICD implant indications, and changes in ICD arrhythmia detection algorithms.

\section{Time-to-shock within 5 years.}

Considering the lifesaving properties of ICD in comparison to its non-negligible complication rate together with the low incidence of $A E$ requiring ICD intervention in $\mathrm{BrS}$ patients implanted prophylactically, up to a 5-year time-to-shock was chosen as accounting for a well-timed implant. Our study found that syncope and a spontaneous type 1 Brs-ECG were significantly associated with time-to-shock of $\leq 5$ years. Therefore, it is not surprising that group lla patients which included those with syncope and a spontaneous type $1 \mathrm{BrS}$-ECG belonged to this 5 years' time-to-shock period. Moreover, the fact that in contrast group IIb patients exhibited their AE more than 5 years after implantation is in congruence with the lower risk of $A E$ found in group IIb as compared to group lla patients(8).

Our study showed that $96 \%$ of female patients vs. $75 \%$ of males had their $A E^{\prime} s \leq 5$ years after ICD implant. In our recent paper(9) we discussed several factors suggesting a more aggressive course of the disease in females. This should support an early implantation of ICD in females found to be at high risk.

\section{Time-to-shock Score}


The time-to-shock score (TScore) was created to help the identification of patients who will need an ICD implant with the shortest delays. The significant risk factors found in our study to be associated with a time-to-shock $\leq 5$ years were attributed a score according to their statistical significance. Because female gender had a borderline significance $(p=0.052)$, which could be a result of the low number of females included in the study, we created two scores one including gender and one excluding it. Both scores showed high prediction rates for $A E \leq 5$ years after ICD implant, yet the gender augmented score showed a more significant trend with a higher predictive value for the maximal score ( $85 \%$ for the maximal score in the minimal scoring system vs. $100 \%$ for the gender augmented system). As indicated in Figure 3, the absence of any of these risk factors, results in a risk of $~ 50 \%$ chance of exhibiting an AE $\leq 5$ years after ICD implant. Thus, patients with a score of 0 could be implanted less urgently. On the other hand, a maximal score of 4 (i.e. a female with syncope and a spontaneous type 1 BrS-ECG) in the gender augmented system should lead to ICD implant with the shortest delays. The value of this TScore should be further validated and assessed prospectively in future studies, where the question of the influence of gender could also be assessed more accurately.

\section{Limitations}

The present study by nature is a retrospective cumulative analysis of results from the largest EP-centers with experience with BrS. The decision to implant a prophylactic ICD in those patients who did not fulfill class II indications was left to the discretion of the treating physician. We acknowledge that defining risk factors without a comparative group of asymptomatic patients is problematic and that the results should be prospectively tested in future studies. Also, our cohort was probably not powered enough to assess the influence of female gender as resulted in a borderline significance for a time to shock of less than 5 years.

\section{Conclusion}

The present study describes for the first time, in a large cohort of $\mathrm{BrS}$ patients with $A E^{\prime} \mathrm{s}$ documented after prophylactic ICD implantation, the characteristics of those who exhibited their AE within 5 years. Two factors (syncope and spontaneous type $1 \mathrm{BrS}-\mathrm{ECG}$ ) were found to be associated with this time-to-shock delay. A score based on these factors is proposed and should be assessed prospectively. 


\section{REFERENCES}

1. Milman A, Andorin A, Gourraud JB, Sacher F, Mabo P, Kim SH, et al. Age of First Arrhythmic Event in Brugada Syndrome: Data From the SABRUS (Survey on Arrhythmic Events in Brugada Syndrome) in 678 Patients. Circ Arrhythm Electrophysiol. 2017;10(12).

2. Milman A, Andorin A, Gourraud JB, Postema PG, Sacher F, Mabo P, et al. Profile of patients with Brugada syndrome presenting with their first documented arrhythmic event: Data from the Survey on Arrhythmic Events in BRUgada Syndrome (SABRUS). Heart Rhythm. 2018;15(5):716-24.

3. Priori SG, Blomstrom-Lundqvist C, Mazzanti A, Blom N, Borggrefe M, Camm J, et al. 2015 ESC Guidelines for the management of patients with ventricular arrhythmias and the prevention of sudden cardiac death: The Task Force for the Management of Patients with Ventricular Arrhythmias and the Prevention of Sudden Cardiac Death of the European Society of Cardiology (ESC). Endorsed by: Association for European Paediatric and Congenital Cardiology (AEPC). Eur Heart J. 2015;36(41):2793-867.

4. Sacher F, Probst V, lesaka Y, Jacon P, Laborderie J, Mizon-Gerard F, et al. Outcome after implantation of a cardioverter-defibrillator in patients with Brugada syndrome: a multicenter study. Circulation. 2006;114(22):2317-24.

5. Sarkozy A, Boussy T, Kourgiannides G, Chierchia GB, Richter S, De Potter T, et al. Long-term follow-up of primary prophylactic implantable cardioverter-defibrillator therapy in Brugada syndrome. Eur Heart J. 2007;28(3):334-44.

6. Sacher F, Probst V, Maury P, Babuty D, Mansourati J, Komatsu Y, et al. Outcome after implantation of a cardioverter-defibrillator in patients with Brugada syndrome: a multicenter study-part 2. Circulation. 2013;128(16):1739-47. 
7. Probst V, Veltmann C, Eckardt L, Meregalli PG, Gaita F, Tan HL, et al. Long-term prognosis of patients diagnosed with Brugada syndrome: Results from the FINGER Brugada Syndrome Registry. Circulation. 2010;121(5):635-43.

8. Takagi M, Sekiguchi Y, Yokoyama Y, Aihara N, Hiraoka M, Aonuma K, et al. Long-term prognosis in patients with Brugada syndrome based on Class II indication for implantable cardioverter-defibrillator in the HRS/EHRA/APHRS Expert Consensus Statement: multicenter study in Japan. Heart Rhythm. 2014;11(10):1716-20.

9. Milman A, Gourraud JB, Andorin A, Postema PG, Sacher F, Mabo P, et al. Gender differences in patients with Brugada syndrome and arrhythmic events: Data from a survey on arrhythmic events in 678 patients. Heart Rhythm. 2018;15(10):1457-65. 
Table 1. Comparison of the median time-to-shock by different patient characteristics.

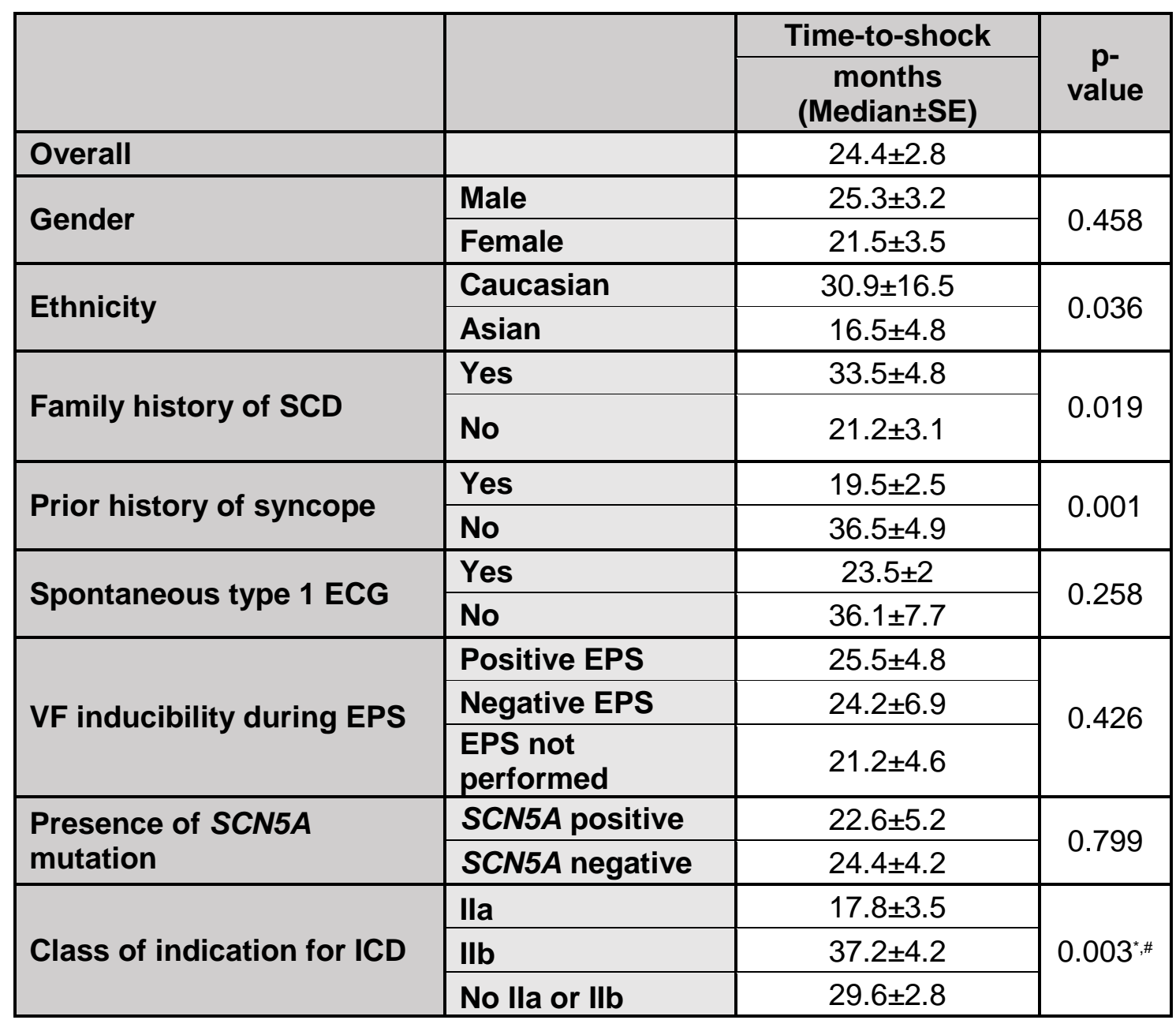

- Ila vs. Ilb, $\mathrm{P}=0.001 ;$ \# Ila vs. No, $\mathrm{P}=0.058$ 
Table 2. Characteristics of patients in respect to the appropriate time-to-shock (less or more than 5 years) delivery.

\begin{tabular}{|c|c|c|c|c|}
\hline & & \multicolumn{2}{|c|}{ Time to $\mathrm{AE}$} & \multirow[b]{2}{*}{ p-value } \\
\hline & & $\begin{array}{l}\leq 5 \text { years } \\
193(76.6)\end{array}$ & $\begin{array}{l}>5 \text { years } \\
59(23.4)\end{array}$ & \\
\hline \multirow{2}{*}{ Gender } & Male & $171(88.6)$ & $58(98.3)$ & \multirow{2}{*}{0.045} \\
\hline & Female & $22(11.4)$ & $1(1.7)$ & \\
\hline \multirow{4}{*}{ Ethnicity } & Caucasian & $119(61.7)$ & $41(69.5)$ & \multirow{2}{*}{0.48} \\
\hline & Asian & $62(32.1)$ & $16(27.1)$ & \\
\hline & Other & $4(2.1)$ & $0(0)$ & \\
\hline & Unknown & $8(4.1)$ & $2(3.4)$ & 0.613 \\
\hline \multirow{3}{*}{ Family history of SCD } & Yes & $52(26.9)$ & $20(33.9)$ & \multirow{3}{*}{$\begin{array}{l}0.278 \\
0.571\end{array}$} \\
\hline & No & $122(63.2)$ & $31(52.5)$ & \\
\hline & Unknown & $19(9.8)$ & $8(13.6)$ & \\
\hline \multirow{2}{*}{ Prior history of syncope } & Yes & 133(68.9) & $26(44.1)$ & \multirow{2}{*}{0.001} \\
\hline & No & $60(31.1)$ & $33(55.9)$ & \\
\hline \multirow{2}{*}{ Spontaneous type 1 ECG } & Yes & $141(73.1)$ & $34(57.6)$ & \multirow{2}{*}{0.037} \\
\hline & No & $52(26.9)$ & $25(42.4)$ & \\
\hline \multirow{3}{*}{ VF inducibility during EPS } & Not performed & $42(21.8)$ & $10(16.9)$ & 0.538 \\
\hline & Positive EPS & 107(70.9) & $37(75.5)$ & \multirow{2}{*}{0.529} \\
\hline & Negative EPS & $44(29.1)$ & $12(24.5)$ & \\
\hline \multirow{3}{*}{ Presence of SCN5A mutation } & Not performed & $60(31.1)$ & $24(40.7)$ & 0.226 \\
\hline & SCN5A positive & $47(35.3)$ & $14(40)$ & \multirow{2}{*}{0.609} \\
\hline & SCN5A negative & $86(64.7)$ & $21(60)$ & \\
\hline
\end{tabular}


Figure 1. Kaplan-Meier curves for the entire time span. The percentage of patients without an AE by months of Follow up

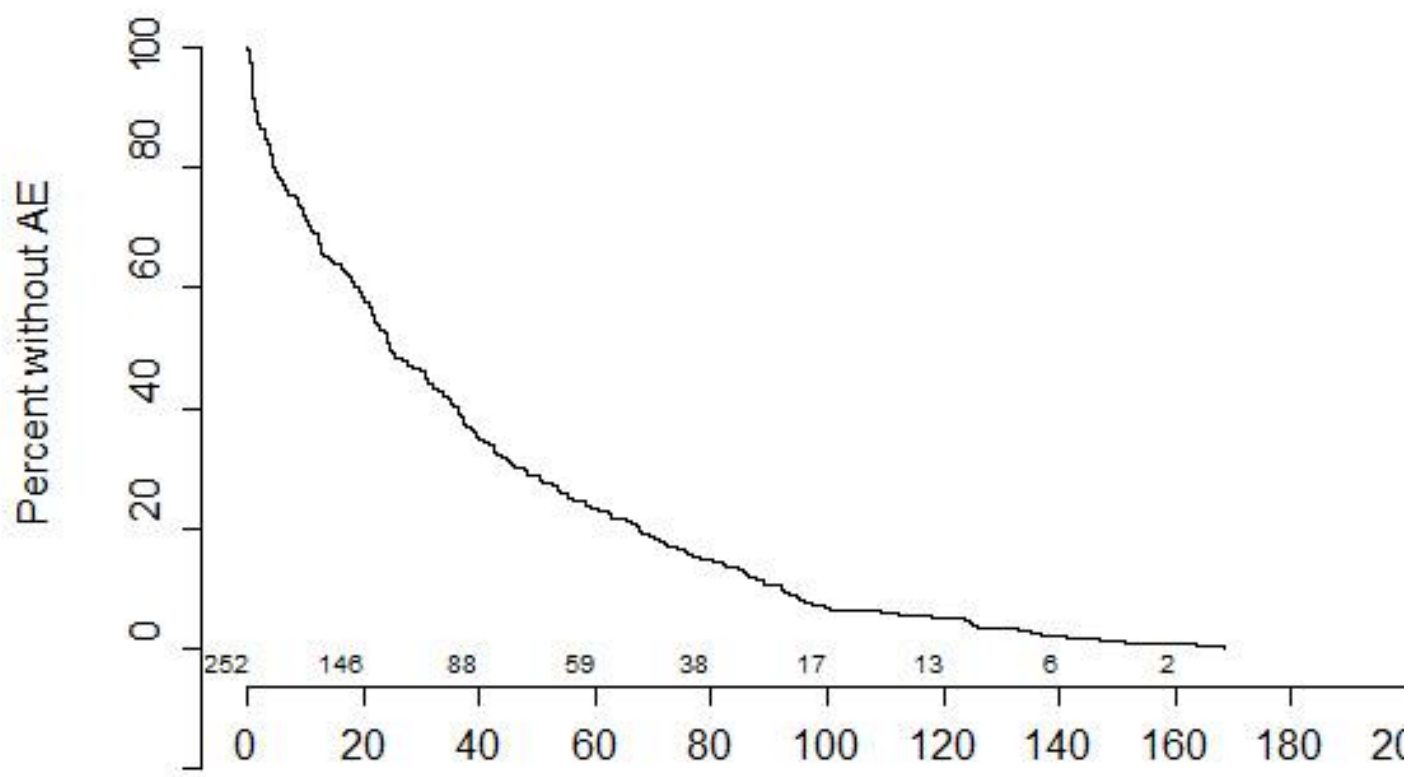

Follow up time (months) 
Figure 2. Median time-to-shock by different parameters. The median time-to-shock for the overall group was $24.4 \pm 2.8$ months. The figure displays the comparison of the median timeto-shock by different patient characteristics: gender, ethnicity, symptoms, ECG type, family history of SCD, mutation, EPS results and ICD indication. (see text for elaboration).

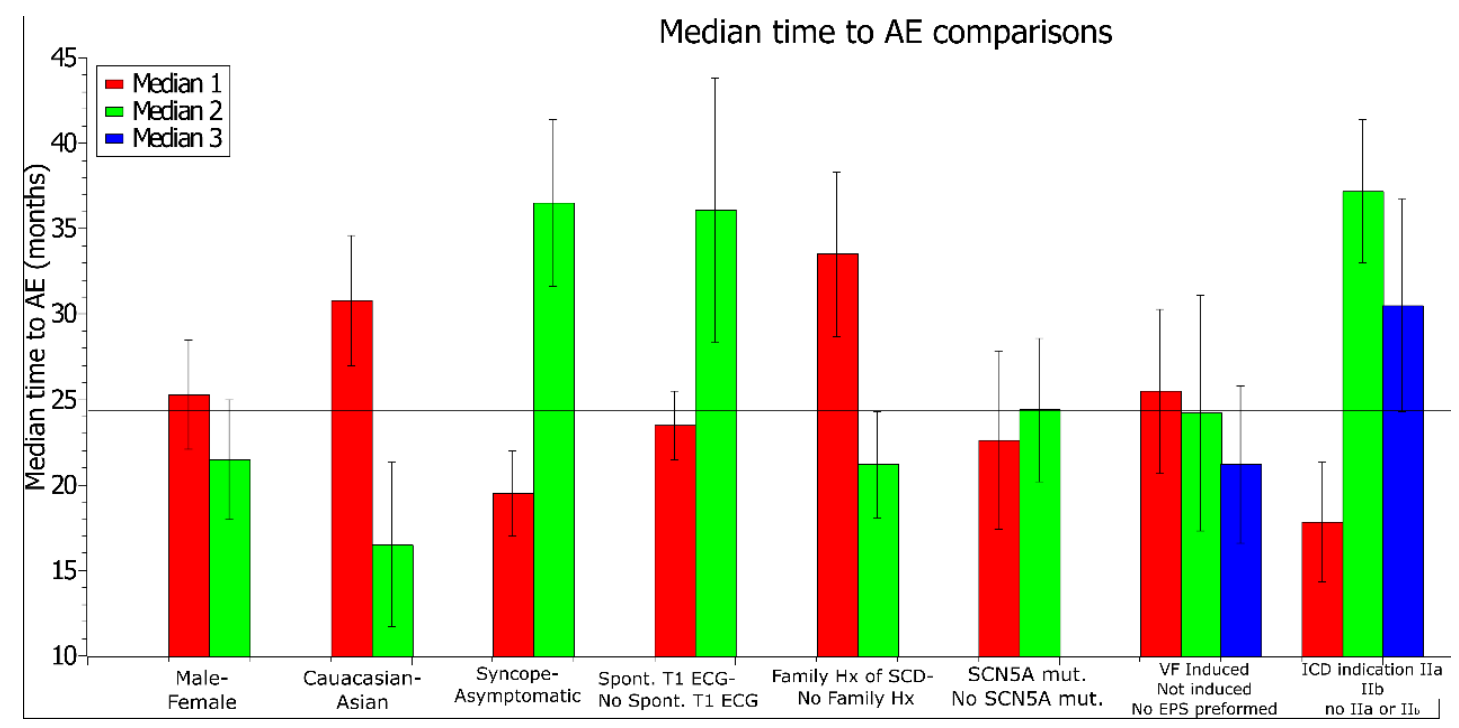


Figure 3. Predictors of $\leq$ than 5 years to shock (OR) Univariate logistic regression for factors favoring $\leq$ than 5 years to shock delivery.

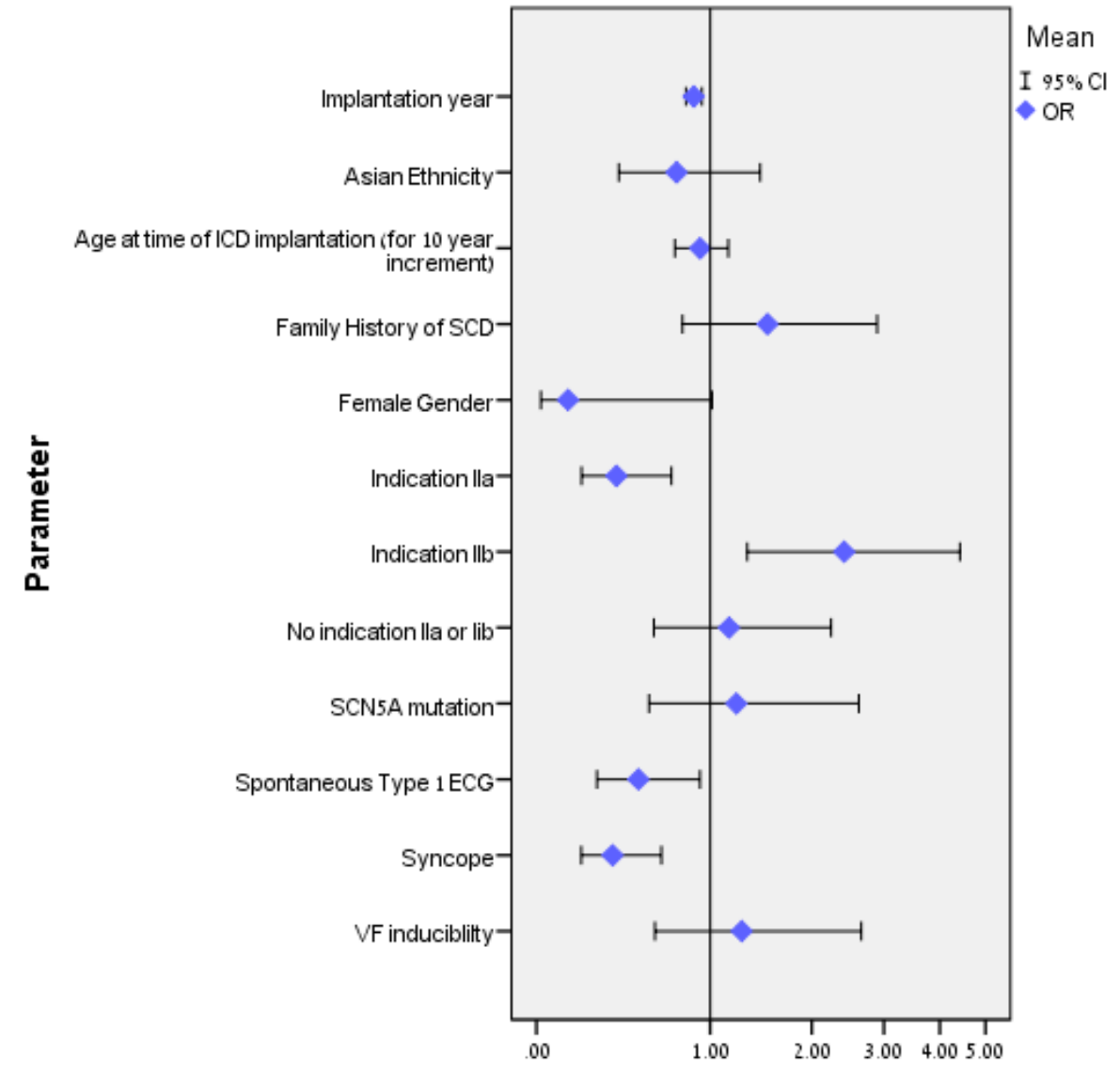


Figure 4. TScore - The Time-to-Shock Score (TScore). Panel A: This risk score sums the following risk factors found to have significance for an earlier AE after a prophylactic ICD implantation: One point is given for either prior syncope or the presence of a spontaneous type 1 Brugada-ECG. Panel B: A gender augmented score, using both the above risk factors and 2 points for female gender. P-value for trend between the score and the probability $<0.001$ for both scores.
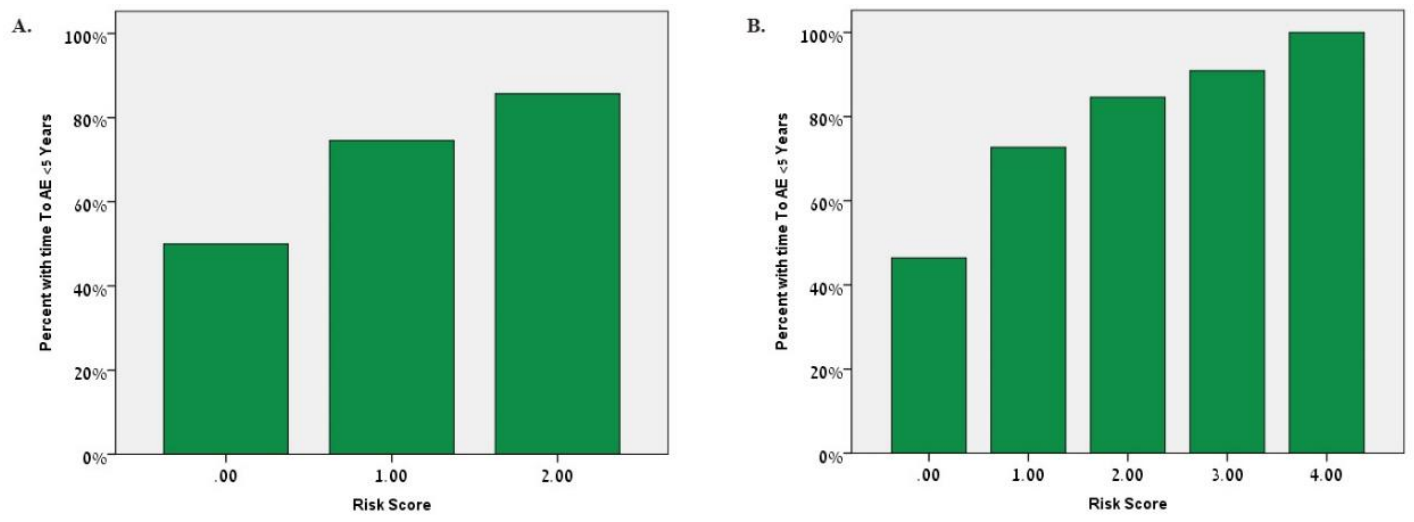
Time-to-First Appropriate Shock in Patients Implanted Prophylactically with an Implantable Cardioverter Defibrillator:

Data from the Survey on Arrhythmic Events in BRUgada Syndrome (SABRUS)

Anat Milman MD PhD ${ }^{1}$, Aviram Hochstadt $\mathrm{MD}^{2}$, Antoine Andorin $\mathrm{MD}^{3,4}$, JeanBaptiste Gourraud MD PhD ${ }^{3,4}$, Frederic Sacher MD ${ }^{5}$, Philippe Mabo MD ${ }^{6}$, SungHwan Kim MD , Giulio Conte MD PhD ${ }^{8}$, Elena Arbelo MD PhD ${ }^{9}$, Tsukasa Kamakura MD PhD ${ }^{10}$, Takeshi Aiba MD PhD ${ }^{10}$, Carlo Napolitano MD PhD ${ }^{4,11}$, Carla Giustetto $\mathrm{MD}^{12}$, Isabelle Denjoy $\mathrm{MD}^{4,13}$, Jimmy JM Juang MD PhD ${ }^{14}$, Shingo Maeda MD PhD ${ }^{15}$, Yoshihide Takahashi MD PhD ${ }^{15}$, Eran Leshem MD ${ }^{1,16}$, Yoav Michowitz MD ${ }^{1}$, Michael Rahkovich MD ${ }^{1,17}$, Camilla H. Jespersen MD ${ }^{4,18,19}$, Yanushi D. Wijeyeratne MD ${ }^{4,20}$, Jean Champagne $\mathrm{MD}^{21}$, Leonardo Calo MD², Zhengrong Huang MD PhD², Yuka Mizusawa MD ${ }^{4,24}$, Pieter G. Postema MD PhD ${ }^{4,24}$, Ramon Brugada MD PhD ${ }^{25}$, Arthur A.M. Wilde MD PhD ${ }^{4,24}$, Gan-Xin Yan MD PhD ${ }^{26}$, Elijah R. Behr MD",20, Jacob TfeltHansen MD DMSc ${ }^{4,18,19}$, Kenzo Hirao MD PhD ${ }^{15}$, Christian Veltmann MD²7, Antoine Leenhardt MD ${ }^{4,13}$, Domenico Corrado MD PhD ${ }^{4,28}$, Fiorenzo Gaita MD ${ }^{12}$, Silvia G. Priori MD PhD ${ }^{4,11,29}$, Kengo F. Kusano MD PhD ${ }^{10}$, Masahiko Takagi MD PhD ${ }^{30}$, Pietro Delise MD ${ }^{31}$, Josep Brugada MD PhD ${ }^{9}$, Pedro Brugada MD PhD ${ }^{4,8}$, Gi-Byoung Nam MD PhD ${ }^{32}$, Vincent Probst MD PhD ${ }^{3,4}$, Bernard Belhassen MD ${ }^{1}$

${ }^{1}$ Department of Cardiology, Tel Aviv Medical Center and Sackler Faculty of Medicine, Tel Aviv University, Tel Aviv, Israel

${ }^{2}$ Department of Internal Medicine J, Tel-Aviv Medical Center, Tel Aviv, Israel 
${ }^{3}$ L'institut du Thorax, Service de Cardiologie, CHU de Nantes, Nantes, France

${ }^{4}$ European Reference Network for Rare and Low Prevalence Complex Diseases of the Heart (ERN GUARDHEART; http://guardheart.ern-net.eu)

${ }^{5}$ LIRYC Institute, INSERM 1045, Bordeaux University Hospital, Bordeaux, France

${ }^{6}$ Cardiology and Vascular Disease Division, Rennes University Health Centre, 35033

Rennes Cedex, France

${ }^{7}$ Division of Cardiology, Department of Internal Medicine, College of Medicine, The Catholic University of Korea, Seoul, Korea

${ }^{8}$ Heart Rhythm Management Centre, UZ-VUB, Brussels, Belgium.

${ }^{9}$ Cardiology Department, Cardiovascular Institute, Hospital Clinic and IDIBAPS,

Barcelona, Catalonia, Spain

${ }^{10}$ Division of Arrhythmia and Electrophysiology, Department of Cardiovascular

Medicine, National Cerebral and Cardiovascular Center, Osaka, Japan

${ }^{11}$ Molecular Cardiology, Istituti Clinici Scientifici Maugeri IRCCS, Pavia, Italy.

${ }^{12}$ Division of Cardiology, University of Torino, Department of Medical Sciences, Città della Salute e della Scienza Hospital, Torino, Italy.

${ }^{13}$ Service de Cardiologie et CNMR Maladies Cardiaques Héréditaires Rares, Hôpital Bichat, Paris, and Université Paris Diderot, Sorbonne, Paris, France

${ }^{14}$ Division of Cardiology, Department of Internal Medicine, National Taiwan University Hospital, Taipei, Taiwan

${ }^{15}$ Heart Rhythm Center, Tokyo Medical and Dental University, Tokyo, Japan

${ }^{16}$ Beth Israel Deaconess Medical Center, Boston, Massachusetts, USA

${ }^{17}$ Arrhythmia Services, Sunnybrook Health Sciences Centre,

Toronto, Ontario, Canada. 
${ }^{18}$ The Department of Cardiology, The Heart Centre, Copenhagen University Hospital, Rigshospitalet, Copenhagen, Denmark.

${ }^{19}$ Department of Forensic Medicine, Faculty of Medical Sciences, University of Copenhagen, Denmark

${ }^{20}$ Cardiovascular Sciences, St. George's University of London and Cardiology Clinical Academic Group St. George's University Hospitals NHS Foundation Trust, London, UK ${ }^{21}$ Quebec Heart and Lung Institute, Quebec City, Canada

${ }^{22}$ Division of Cardiology, Policlinico Casilino, Roma, Italy

${ }^{23}$ Department of Cardiology, the First Affiliated Hospital of Xiamen University, Xiamen, Fujian, China.

${ }^{24}$ Heart Centre AMC, Department of clinical and experimental Cardiology, AMC, University of Amsterdam, Amsterdam Netherlands.

${ }^{25}$ Cardiovascular Genetics Center, University of Girona-IDIBGI, Girona, Spain; Medical Science Department, School of Medicine, University of Girona, Girona, Spain; Centro de Investigación Biomédica en Red de Enfermedades Cardiovasculares (CIBERCV), Madrid, Spain.

${ }^{26}$ Lankenau Medical Center, Wynnewood, Pennsylvania, USA

${ }^{27}$ Rhythmology and Electrophysiology, Department of Cardiology, Hannover Medical School, Hannover, Germany

${ }^{28}$ Department of Cardiac, Thoracic and Vascular Sciences University of Padova, Padova, Italy

${ }^{298}$ Department of Molecular Medicine, University of Pavia, Pavia, Italy

${ }^{30}$ Division of Cardiac Arrhythmia, Kansai Medical University Medical Center, Moriguchi, Japan 
${ }^{31}$ Division of Cardiology, Hospital of Peschiera del Garda, Veneto, Italy

${ }^{32}$ Division of Cardiology, Department of Internal Medicine, Asan Medical Center, University of Ulsan College of Medicine, Seoul, Korea

Address for correspondence:

Anat Milman, MD, PhD

Department of Cardiology, Tel Aviv Medical Center

6 Weizman Street, Tel Aviv 6423906, Israel

Telephone: +972-54-3-166-651; Fax: +972-153-52-4-266-856

Email: anatmilman@gmail.com 


\section{ABSTRACT}

\section{Aims.}

Data on predictors of time-to-first appropriate ICD therapy in patients with Brugada syndrome $(\mathrm{BrS})$ and prophylactically implanted ICD's are scarce.

\section{Methods.}

SABRUS is an international survey on $678 \mathrm{BrS}$-patients who experienced arrhythmic event (AE) including 252 patients in whom AE occurred after prophylactic ICD implantation. Analysis was performed on time-to-first appropriate ICD discharge regarding patients' characteristics. Multivariate logistic regression models were utilized to identify which parameters predicted time to arrhythmia $\leq 5$ years.

\section{Results.}

The median time-to-first appropriate ICD therapy was $24.8 \pm 2.8$ months. A shorter time was observed in patients from Asian ethnicity $(p<0.05)$, those with syncope $(p=0.001)$ and those with class Ila indication for ICD ( $p=0.001)$. A longer time was associated with a positive family history of sudden cardiac death $(p<0.05)$.

Multivariate Cox regression revealed shorter time-to-ICD therapy in patients with syncope (OR 1.65, $\mathrm{P}=0.001)$. In 193 patients (76.6\%), therapy was delivered during the first 5 years. Factors associated with this time were syncope (OR $0.36, p=0.001$ ), spontaneous type 1 Brugada ECG (OR 0.5, p<0.05) and class Ila indication (OR 0.38, $\mathrm{p}<0.01$ ) as opposed to class IIb (OR 2.41, $\mathrm{p}<0.01)$. A near-significant trend for female gender was also noted (OR 0.13, $p=0.052$ ). Two score models for prediction of $<5$ years to shock were built.

\section{Conclusions.}

First appropriate therapy in BrS-patients with prophylactic ICD's occurred during the 
first 5 years in $76.6 \%$ of patients. Syncope and spontaneous type 1 Brugada-ECG correlated with a shorter time to ICD therapy.

Key Words: Brugada Syndrome, ICD, appropriate therapy, arrhythmic event 


\section{Condensed abstract.}

SABRUS collected 252 patients in whom AE occurred after prophylactic ICD

implantation. First appropriate ICD therapy occurred during first 5 years in $76.6 \%$ of patients. Syncope and spontaneous type 1 Brugada-ECG (comprising class Ila indication for prophylactic ICD implantation) correlated with shorter time to ICD therapy. 


\section{'What's New?'}

1. In patients with $\mathrm{BrS}$ who had an appropriate shock from a prophylactically implanted ICD, the great majority (76.6\%) received this shock during the first 5 years after ICD implantation.

2. Clinical parameters predicting a shorter time to appropriate shock were syncope and a spontaneous type 1 ECG. A near-significant trend for female gender was also noted.

3. Two score models were built using these parameters to predict the time to first $A E$ and will need to be validated in future studies. 


\section{INTRODUCTION}

Brugada syndrome (Brs) is a well-recognized cause of sudden cardiac death (SCD) particularly in apparently healthy middle-aged males(1). The cause of death is a ventricular tachyarrhythmia usually occurring without precipitating warning signs(2) . Most clinical research on this potentially lethal arrhythmic disease has mainly focused on risk stratification to identify patients at risk who will benefit from an implanted cardioverter-defibrillator (ICD), the most advocated option to prevent SCD.

Present indications for prophylactic ICD implantation in patients with BrS-ECG include(3): 1) Spontaneous type 1 Brugada-ECG pattern and a history of syncope (class Ila indication); 2) Spontaneous or drug-induced type 1 Brugada-ECG with induction of ventricular fibrillation during programmed ventricular stimulation with 2 or 3 extrastimuli (class $\mathrm{Ilb}$ indication). When a patient is identified as complying with these guideline recommendations(3), the most appropriate timing of the implantation is unknown with a double-edged sword decision for implant: too early might expose the patient to possible complications whereas too late might have a detrimental outcome.

SABRUS is a multicenter international survey that collected data on a large cohort ( $n=678$ ) of BrS-patients who experienced AE including 252 patients in whom the AE occurred after a prophylactic ICD implantation.

The present study sought to gain insight into the factors that affect the time-to-first appropriate ICD therapy in all the $252 \mathrm{BrS}$ patients who received a prophylactic ICD. 


\section{METHODS}

Study group. As mentioned in previous papers $(1,2)$, the SABRUS cohort population comprised a total of $678 \mathrm{BrS}$-patients with $\mathrm{AE}$ who were recruited from 23 centers from both 10 Western countries (426 patients; $62.8 \%$ ) and 4 Asian countries (252 patients; $37.2 \%$ ). In 426 patients (group A), the AE was documented during aborted CA while in 252 patients (group B) the AE was documented from an ICD implanted prophylactically following conventional class Ila or Ilb indications(3) (75\% of patients) or non-class Ila or Ilb indications (25\% of patients)(2).

Group B patients comprised the study group of the present study.

The study was approved by the Research Ethics Boards of all participating institutions.

\section{DATA ACQUISITION.}

Anonymous patient information was collected using a predefined questionnaire regarding the following: 1) gender; 2) patient age at time of ICD implantation; 3) date of ICD implantation; 4) date at which the first AE occurred after ICD implantation; 4) ethnicity (Caucasian, Asian, other or unknown); 5) proband status; 6) family history of SCD; 7) prior history of syncope ; 8) presence of spontaneous or drug-induced Brugada-ECG type $1 ; 7$ ) inducibility of sustained ventricular fibrillation (VF) at EP study (EPS) and 9) results of genetic testing for the presence of SNC5A mutation.

DEFINITIONS.

Arrhythmic events: AE was defined as any sustained ventricular tachyarrhythmia triggering appropriate ICD shock therapy.

STATISTICAL ANALYSIS. 
Estimation of median time to AE for ordinal variables was done using Kaplan-Meier curves; significance of the difference between two curves was calculated using the log-rank test. Multivariate time to AE analysis and analysis of continuous parameters was done using Cox regression models. Calculation of each parameter effect on probability of time to $\mathrm{AE}$ being $>5$ years was done using binary logistic regression models. To prevent detection bias due to patients with longer follow up having a longer time to $A E$, we added the year of ICD implantation in all of the multivariate analyses to cancel out this effect. Out of the multivariate logistic regression model we built prediction scores using the relative odd ratios as a guide to each parameter score. The trend between the scores and the above probability was assessed using Mantel-Haenszel test of trend and the highest-ranking scores were selected. Time to $\mathrm{AE}$ is shown as Median $\pm \mathrm{SE}$. $\mathrm{P}$-values were considered significant when $\mathrm{P}<0.05$, all calculations were done using SPSS v.24 from IBM, Armonk, Virginia.

\section{RESULTS}

Study group. The study group comprised 252 patients aged 1.1-77.5 (mean $46.1 \pm$ 13.3) years at time of $A E$, most being males ( $n=229,91 \%)$ and Caucasians ( $n=160$, $63.5 \%$ ) (Supplemental Table 1). A positive family history of SCD and a prior history of syncope were present in $29 \%$ and $63 \%$ of patients, respectively. A spontaneous type 1 Brugada-ECG was observed in $69 \%$ of patients. Most of the patients (79\%) underwent an EPS during which VF was inducible in $72 \%$ of them. Genetic testing was performed in $67 \%$ of patients and revealed an SCN5A mutation in $36 \%$ of them. The age at time of ICD implantation ranged from 1-73.2 years (mean $43.4 \pm 13.1$ ). Time-to-shock. The time-to-shock ranged from 0 to 168.4 months (median $24.4 \pm 2.8$ months), Figure 1 shows the Kaplan Meier curves for the entire time span. Table 1 
elaborates the comparison of the median time-to-shock according to different patient characteristics and Figure 2 displays the results. The following two factors were found to be associated with a significantly shorter time-to-shock: Asian vs. Caucasian ethnicity $(16.5 \pm 4.8$ vs. $30.9 \pm 16.5$ months respectively, $\mathrm{P}<0.05)$ and a prior history of syncope vs. being asymptomatic (19.5 \pm 2.5 vs. $36.5 \pm 4.9$ months respectively, $\mathrm{P}=0.001)$. In contrast a positive family history of $\mathrm{SCD}$ resulted in a longer time-to-shock (33.5 \pm 4.8 vs. $21.2 \pm 3.1$ months in patients without such a history, $\mathrm{P}<0.05)$.

In respect to the conventional indications of prophylactic ICD implantation (3), the shortest median time-to-shock was observed in the class Ila subgroup $(17.8 \pm 3.5$ months) as compared to class Ilb subgroup ( $37.2 \pm 4.2$ months, $\mathrm{P}=0.001)$ or to non $\mathrm{Ila} / \mathrm{llb}$ indications (29.6 \pm 2.8 months, $\mathrm{P}=0.058)$ Univariate Cox regression for continuous variables did not find a significant relation between a shorter time-to-shock and patient age at time of ICD implantation $[P=0.285$; odds ratio [OR]. 1.06; 95\% confidence interval (CI). 0.96-1.17]. Multivariate Cox regression was significant for a history of syncope $[P=0.001 ; O R$ 1.65; $95 \% \mathrm{Cl}$ 1.21-2.25] and for year of ICD implantation $[\mathrm{P}<0.001 ; \mathrm{OR} 1.12 ; 95 \% \mathrm{Cl} 1.07-1.16]$ but not for ethnicity or family history of SCD.

Less than $\mathbf{5}$ years-to-shock time. Table 2 shows patients characteristics in respect to a 5 years-to-shock time. In 193 (76.6\%) patients appropriate ICD shock therapy was delivered during the first 5 years. Univariate logistic regression (Figure 3 ) analyses showed that factors favoring this time lag were a prior history of syncope $(P=0.001$, OR. $0.36 ; 95 \% \mathrm{Cl} 0.2-0.65)$, the presence of a spontaneous type 1 Brugada-ECG $(\mathrm{P}<0.05$, OR. $0.5 ; 95 \% \mathrm{Cl} 0.27-0.92)$ and the year of ICD implantation $(\mathrm{P}<0.001 ; \mathrm{OR}$. 
$0.87 ; 95 \% \mathrm{Cl} 0.82-0.94)$. Female gender showed a trend towards shock time less than 5 years ( $\mathrm{P}=0.052$, OR. $0.13 ; 95 \% \mathrm{Cl} 0.02-1.02)$, Multivariate Cox regression analysis was significant for all the aforementioned parameters (Supplemental Table 3). Opposite results were found between the class Ila and IIb indications for prophylactic ICD implantation: a class Ila indication was a significant predictor for $\leq 5$ years-to-appropriate shock ( $\mathrm{P}<0.01$; OR. $0.38 ; 95 \% \mathrm{Cl} 0.2-0.71)$ whereas a class IIb indication was a significant predictor for $>5$ years-to-appropriate shock $(P<0.01 ; O R$. 2.41; 95\% Cl 1.32-4.22) (Figure 3).

Time-to-Shock Score. Taking into consideration the aforementioned patients' characteristics predicting a time-to-shock $\leq 5$ years, their relative odds ratio, and parameter significance, two risks scores were built. One with a history of syncope and spontaneous type 1 Brugada ECG (minimal score) and the second with female gender added, as it had a borderline significance, yet we postulated it could add power to the score (gender augmented score).

These Scores sum the risk factors found to have significance for an earlier AE after a prophylactic ICD implantation. Each risk factor received a score between 1 and 2 and the sum gives the percentage of patients who received an appropriate therapy during the first 5 years from the implant (Figure 4). One point is given for either prior syncope or the presence of a spontaneous type 1 Brugada-ECG, and for the gender augmented score - 2 points were added for female gender. The scores range between 0 and 2 for the minimal score and 0 and 4 for the gender augmented score. A score of 0 was found in $50.0 \%$ of patients using the minimal score and in $46.4 \%$ of patients using the gender augmented score. A maximal score (2 in the minimal score system and 4 in the gender augmented system) was observed in $85 \%$ and $100 \%$ of 
patients, respectively. The trend between the score and the percentage of patients with time to shock less than 5 years was highly significant for both scores $(p<0.001$ for both) but reached a higher level for the gender augmented score (MantelHaenszel statistics of 16 and 20.1 for the minimal and the gender augmented scores, accordingly).

\section{DISCUSSION}

Our study showed that the median time-to-first appropriate ICD therapy in the 252 BrS patients who received a prophylactic ICD was $24.8 \pm 2.8$ months. The shortest times were observed in patients of Asian ethnicity, in those with prior syncope and in those who had a class Ila indication for ICD implantation. The longest time was associated with a positive family history of $\mathrm{SCD}$. In $>3$ quarters of the study patients, appropriate ICD therapy was delivered during the first 5 years after implantation, especially in patients with a female gender, those with a prior syncope and those with a spontaneous type 1 Brugada-ECG. Two score models for predicting a time-toshock $\leq 5$ years were built according to the significance of the parameters; one included syncope and a type 1 Brugada ECG and the second included female gender which had a borderline significance and resulted in a 100\% accuracy when patients exhibited all these characteristics.

\section{Time-to-shock.}

The literature regarding the time-to-first appropriate shock therapy in BrS patients implanted prophylactically with an ICD is scarce. Only 3 studies report their results on small patient cohorts (ranging from 7 to 34 patients)(4-6). Sarkozy et al.(5) found a mean time-to-first appropriate therapy of 13 months ( 3 days to 4 years) in 7 male patients including 3 with a history of syncope. They did not find a significant 
predictor of appropriate shock-free survival(5). In an earlier study, Sacher et al.(4) demonstrated that the asymptomatic group $(n=5)$ had a shorter median time-toshock (16 months) than the syncope group ( $n=9)$ (24 months)(4). However, in a latter larger study by the same group with prolonged follow-up duration, time-to-shock lengthened with no difference found between the symptomatic ( 47 months, $n=22$ ) and asymptomatic (45 months, $\mathrm{n}=12$ ) groups(6).

In the present study which involved the largest cohort population with AEs documented after prophylactic ICD implantation $(n=252)$, the median time-to-shock was 24.8 months. Asian ethnicity and a history of syncope were predictors of a shorter time-to-shock, suggesting these factors should be taken into consideration when contemplating ICD implantation. This is consistent with the fact that group Ila patients had the shortest time-to-shock.

By multivariate logistic regression the presence of syncope was found to correlate with a shorter time-to-shock $(19.5 \pm 2.5$ months vs. $36.5 \pm 4.9$ months in asymptomatic patients, $\mathrm{P}<0.001)$. It is noteworthy that these results are in agreement with those of the FINGER study(7) where time-to-first event was reported to be significantly shorter in the syncope group patients than in the asymptomatic group. In the present study, a positive family history of SCD correlated with a longer timeto-shock, however these findings should be considered with caution since they were seen only in the univariate analysis and not in the multivariate one. One possible explanation could be a biased decision taken by the referring patient's physician who considered a family history of SCD as a major risk factor. On the other hand, we already stressed elsewhere the problematic definition of family history of SCD in our study(2). ICD implant year was a predictor of early $A E$, mostly due to longer follow- 
up in patients that had an ICD implanted in the past, although this finding might also represent different trends in ICD implant indications, and changes in ICD arrhythmia detection algorithms.

\section{Time-to-shock within 5 years.}

Considering the lifesaving properties of ICD in comparison to its non-negligible complication rate together with the low incidence of $A E$ requiring ICD intervention in BrS patients implanted prophylactically, up to a 5-year time-to-shock was chosen as accounting for a well-timed implant. Our study found that syncope and a spontaneous type 1 Brs-ECG were significantly associated with time-to-shock of $\leq 5$ years. Therefore, it is not surprising that group Ila patients which included those with syncope and a spontaneous type 1 BrS-ECG belonged to this 5 years' time-to-shock period. Moreover, the fact that in contrast group IIb patients exhibited their AE more than 5 years after implantation is in congruence with the lower risk of AE found in group IIb as compared to group Ila patients(8).

Our study showed that $96 \%$ of female patients vs. $75 \%$ of males had their $A E^{\prime} s \leq 5$ years after ICD implant. In our recent paper(9) we discussed several factors suggesting a more aggressive course of the disease in females. This should support an early implantation of ICD in females found to be at high risk.

\section{Time-to-shock Score}

The time-to-shock score (TScore) was created to help the identification of patients who will need an ICD implant with the shortest delays. The significant risk factors found in our study to be associated with a time-to-shock $\leq 5$ years were attributed a score according to their statistical significance. Because female gender had a borderline significance $(p=0.052)$, which could be a result of the low number of 
females included in the study, we created two scores one including gender and one excluding it. Both scores showed high prediction rates for $A E \leq 5$ years after ICD implant, yet the gender augmented score showed a more significant trend with a higher predictive value for the maximal score $(85 \%$ for the maximal score in the minimal scoring system vs. $100 \%$ for the gender augmented system). As indicated in Figure 3 , the absence of any of these risk factors, results in a risk of $\sim 50 \%$ chance of exhibiting an $A E \leq 5$ years after ICD implant. Thus, patients with a score of 0 could be implanted less urgently. On the other hand, a maximal score of 4 (i.e. a female with syncope and a spontaneous type $1 \mathrm{BrS}-\mathrm{ECG}$ ) in the gender augmented system should lead to ICD implant with the shortest delays. The value of this TScore should be further validated and assessed prospectively in future studies, where the question of the influence of gender could also be assessed more accurately.

\section{Limitations}

The present study by nature is a retrospective cumulative analysis of results from the largest EP-centers with experience with $\mathrm{BrS}$. The decision to implant a prophylactic ICD in those patients who did not fulfill class II indications was left to the discretion of the treating physician. We acknowledge that defining risk factors without a comparative group of asymptomatic patients is problematic and that the results should be prospectively tested in future studies. Also, our cohort was probably not powered enough to assess the influence of female gender as resulted in a borderline significance for a time to shock of less than 5 years.

\section{Conclusion}

The present study describes for the first time, in a large cohort of $\mathrm{BrS}$ patients with $A E$ 's documented after prophylactic ICD implantation, the characteristics of those 
who exhibited their AE within 5 years. Two factors (syncope and spontaneous type 1 BrS-ECG) were found to be associated with this time-to-shock delay. A score based on these factors is proposed and should be assessed prospectively. 


\section{REFERENCES}

1. Milman A, Andorin A, Gourraud JB, Sacher F, Mabo P, Kim SH, et al. Age of First Arrhythmic Event in Brugada Syndrome: Data From the SABRUS (Survey on Arrhythmic Events in Brugada Syndrome) in 678 Patients. Circ Arrhythm Electrophysiol. 2017;10(12).

2. Milman A, Andorin A, Gourraud JB, Postema PG, Sacher F, Mabo P, et al. Profile of patients with Brugada syndrome presenting with their first documented arrhythmic event: Data from the Survey on Arrhythmic Events in BRUgada Syndrome (SABRUS). Heart Rhythm. 2018;15(5):716-24.

3. Priori SG, Blomstrom-Lundqvist C, Mazzanti A, Blom N, Borggrefe M, Camm J, et al. 2015 ESC Guidelines for the management of patients with ventricular arrhythmias and the prevention of sudden cardiac death: The Task Force for the Management of Patients with Ventricular Arrhythmias and the Prevention of Sudden Cardiac Death of the European Society of Cardiology (ESC). Endorsed by: Association for European Paediatric and Congenital Cardiology (AEPC). Eur Heart J. 2015;36(41):2793-867 .

4. Sacher F, Probst V, lesaka Y, Jacon P, Laborderie J, Mizon-Gerard F, et al. Outcome after implantation of a cardioverter-defibrillator in patients with Brugada syndrome: a multicenter study. Circulation. 2006;114(22):2317-24.

5. Sarkozy A, Boussy T, Kourgiannides G, Chierchia GB, Richter S, De Potter T, et al. Long-term follow-up of primary prophylactic implantable cardioverterdefibrillator therapy in Brugada syndrome. Eur Heart J. 2007;28(3):334-44. 
6. Sacher F, Probst V, Maury P, Babuty D, Mansourati J, Komatsu Y, et al.

Outcome after implantation of a cardioverter-defibrillator in patients with Brugada syndrome: a multicenter study-part 2. Circulation. 2013;128(16):1739-47.

7. Probst V, Veltmann C, Eckardt L, Meregalli PG, Gaita F, Tan HL, et al. Longterm prognosis of patients diagnosed with Brugada syndrome: Results from the FINGER Brugada Syndrome Registry. Circulation. 2010;121(5):635-43.

8. Takagi M, Sekiguchi Y, Yokoyama Y, Aihara N, Hiraoka M, Aonuma K, et al. Long-term prognosis in patients with Brugada syndrome based on Class II indication for implantable cardioverter-defibrillator in the HRS/EHRA/APHRS Expert Consensus Statement: multicenter study in Japan. Heart Rhythm. 2014;11(10):1716-20.

9. Milman A, Gourraud JB, Andorin A, Postema PG, Sacher F, Mabo P, et al. Gender differences in patients with Brugada syndrome and arrhythmic events: Data from a survey on arrhythmic events in 678 patients. Heart Rhythm.

2018;15(10):1457-65. 
Table 1. Comparison of the median time-to-shock by different patient characteristics.

\begin{tabular}{|c|c|c|c|}
\hline & & $\begin{array}{c}\text { Time-to-shock } \\
\text { months } \\
\text { (Median } \pm S E \text { ) }\end{array}$ & $\begin{array}{c}\mathrm{p}- \\
\text { value }\end{array}$ \\
\hline Overall & & $24.4 \pm 2.8$ & \\
\hline \multirow{2}{*}{ Gender } & Male & $25.3 \pm 3.2$ & \multirow{2}{*}{0.458} \\
\hline & Female & $21.5 \pm 3.5$ & \\
\hline \multirow{2}{*}{ Ethnicity } & Caucasian & $30.9 \pm 16.5$ & \multirow{2}{*}{0.036} \\
\hline & Asian & $16.5 \pm 4.8$ & \\
\hline \multirow{2}{*}{ Family history of SCD } & Yes & $33.5 \pm 4.8$ & \multirow{2}{*}{0.019} \\
\hline & No & $21.2 \pm 3.1$ & \\
\hline \multirow{2}{*}{ Prior history of syncope } & Yes & $19.5 \pm 2.5$ & \multirow{2}{*}{0.001} \\
\hline & No & $36.5 \pm 4.9$ & \\
\hline \multirow{2}{*}{ Spontaneous type 1 ECG } & Yes & $23.5 \pm 2$ & \multirow{2}{*}{0.258} \\
\hline & No & $36.1 \pm 7.7$ & \\
\hline \multirow{3}{*}{ VF inducibility during EPS } & Positive EPS & $25.5 \pm 4.8$ & \multirow{3}{*}{0.426} \\
\hline & Negative EPS & $24.2 \pm 6.9$ & \\
\hline & $\begin{array}{l}\text { EPS not } \\
\text { performed }\end{array}$ & $21.2 \pm 4.6$ & \\
\hline \multirow{2}{*}{$\begin{array}{l}\text { Presence of SCN5A } \\
\text { mutation }\end{array}$} & SCN5A positive & $22.6 \pm 5.2$ & \multirow{2}{*}{0.799} \\
\hline & SCN5A negative & $24.4 \pm 4.2$ & \\
\hline \multirow{3}{*}{ Class of indication for ICD } & Ila & $17.8 \pm 3.5$ & \multirow{3}{*}{ 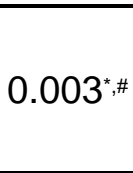 } \\
\hline & Ilb & $37.2 \pm 4.2$ & \\
\hline & No lla or llb & $29.6 \pm 2.8$ & \\
\hline
\end{tabular}

- Ila vs. Ilb, $\mathrm{P}=0.001$; \# Ila vs. No, $\mathrm{P}=0.058$ 
Table 2. Characteristics of patients in respect to the appropriate time-to-shock (less or more than 5 years) delivery.

\begin{tabular}{|c|c|c|c|c|}
\hline & & \multicolumn{2}{|c|}{ Time to $\mathrm{AE}$} & \multirow[b]{2}{*}{ p-value } \\
\hline & & $\begin{array}{l}\leq 5 \text { years } \\
193(76.6)\end{array}$ & $\begin{array}{l}>5 \text { years } \\
59(23.4)\end{array}$ & \\
\hline \multirow{2}{*}{ Gender } & Male & $171(88.6)$ & $58(98.3)$ & \multirow{2}{*}{0.045} \\
\hline & Female & $22(11.4)$ & $1(1.7)$ & \\
\hline \multirow{4}{*}{ Ethnicity } & Caucasian & $119(61.7)$ & $41(69.5)$ & \multirow{2}{*}{0.48} \\
\hline & Asian & $62(32.1)$ & $16(27.1)$ & \\
\hline & Other & $4(2.1)$ & $0(0)$ & \\
\hline & Unknown & $8(4.1)$ & $2(3.4)$ & 0.613 \\
\hline \multirow{3}{*}{ Family history of SCD } & Yes & $52(26.9)$ & $20(33.9)$ & \multirow{3}{*}{$\begin{array}{l}0.278 \\
0.571\end{array}$} \\
\hline & No & $122(63.2)$ & $31(52.5)$ & \\
\hline & Unknown & $19(9.8)$ & $8(13.6)$ & \\
\hline \multirow{2}{*}{ Prior history of syncope } & Yes & 133(68.9) & $26(44.1)$ & \multirow{2}{*}{0.001} \\
\hline & No & $60(31.1)$ & $33(55.9)$ & \\
\hline \multirow{2}{*}{ Spontaneous type 1 ECG } & Yes & $141(73.1)$ & $34(57.6)$ & \multirow{2}{*}{0.037} \\
\hline & No & $52(26.9)$ & $25(42.4)$ & \\
\hline \multirow{3}{*}{ VF inducibility during EPS } & Not performed & $42(21.8)$ & $10(16.9)$ & 0.538 \\
\hline & Positive EPS & $107(70.9)$ & $37(75.5)$ & \multirow{2}{*}{0.529} \\
\hline & Negative EPS & $44(29.1)$ & $12(24.5)$ & \\
\hline \multirow{3}{*}{ Presence of SCN5A mutation } & Not performed & $60(31.1)$ & $24(40.7)$ & \multirow{3}{*}{$\begin{array}{l}0.226 \\
0.609\end{array}$} \\
\hline & SCN5A positive & $47(35.3)$ & $14(40)$ & \\
\hline & SCN5A negative & $86(64.7)$ & $21(60)$ & \\
\hline
\end{tabular}


Figure 1. Kaplan-Meier curves for the entire time span. The percentage of patients without an AE by months of Follow up

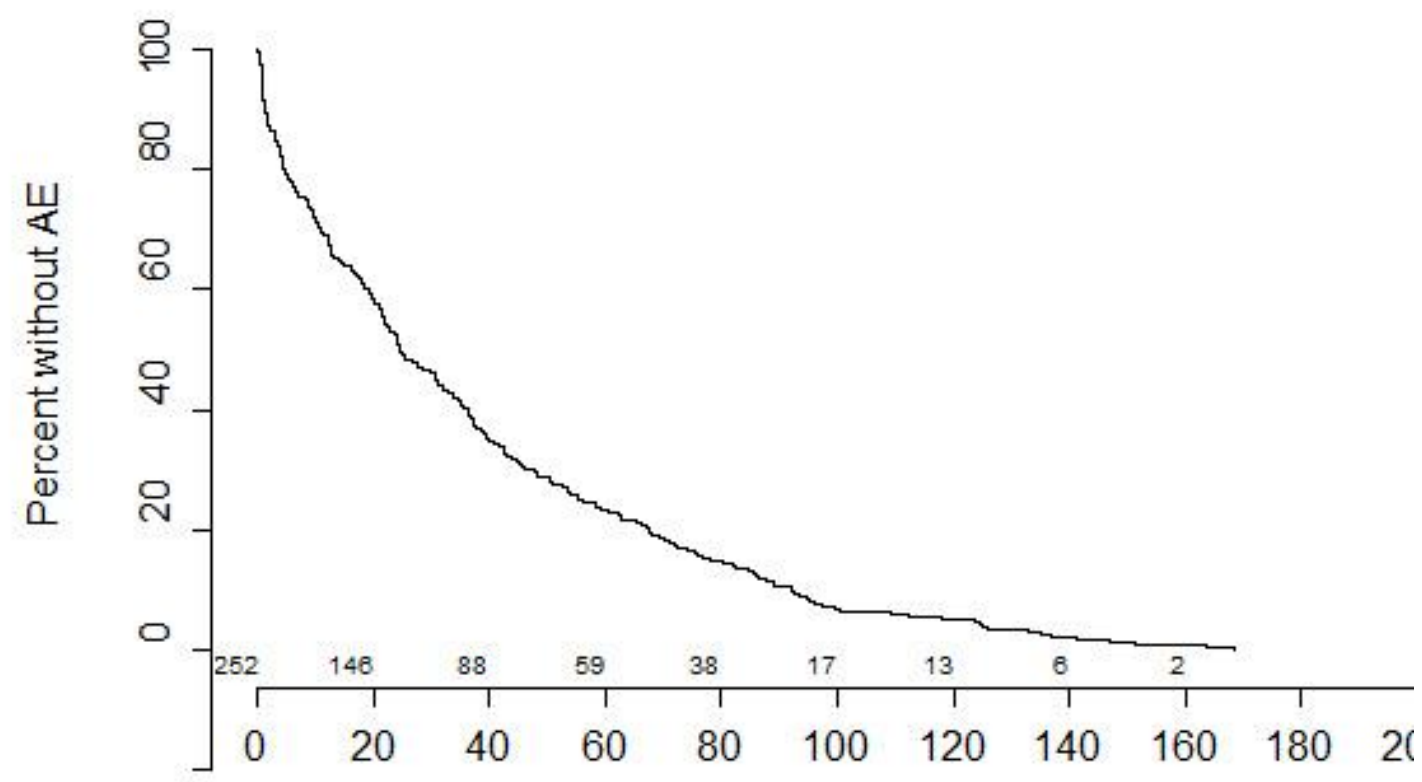

Follow up time (months) 
Figure 2. Median time-to-shock by different parameters. The median time-to-shock for the overall group was $24.4 \pm 2.8$ months. The figure displays the comparison of the median time-to-shock by different patient characteristics: gender, ethnicity, symptoms, ECG type, family history of SCD, mutation, EPS results and ICD indication. (see text for elaboration).

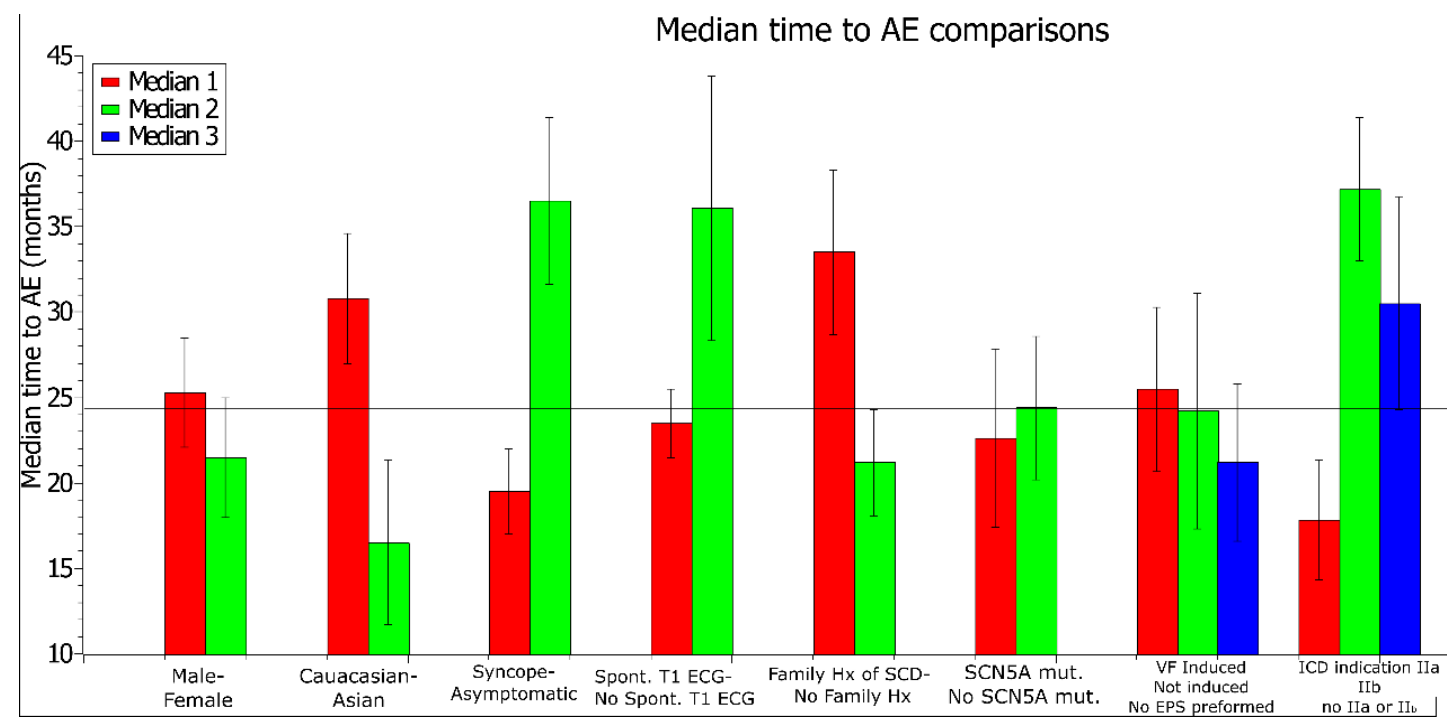


Figure 3. Predictors of $\leq$ than 5 years to shock (OR) Univariate logistic regression for factors favoring $\leq$ than $\mathbf{5}$ years to shock delivery.

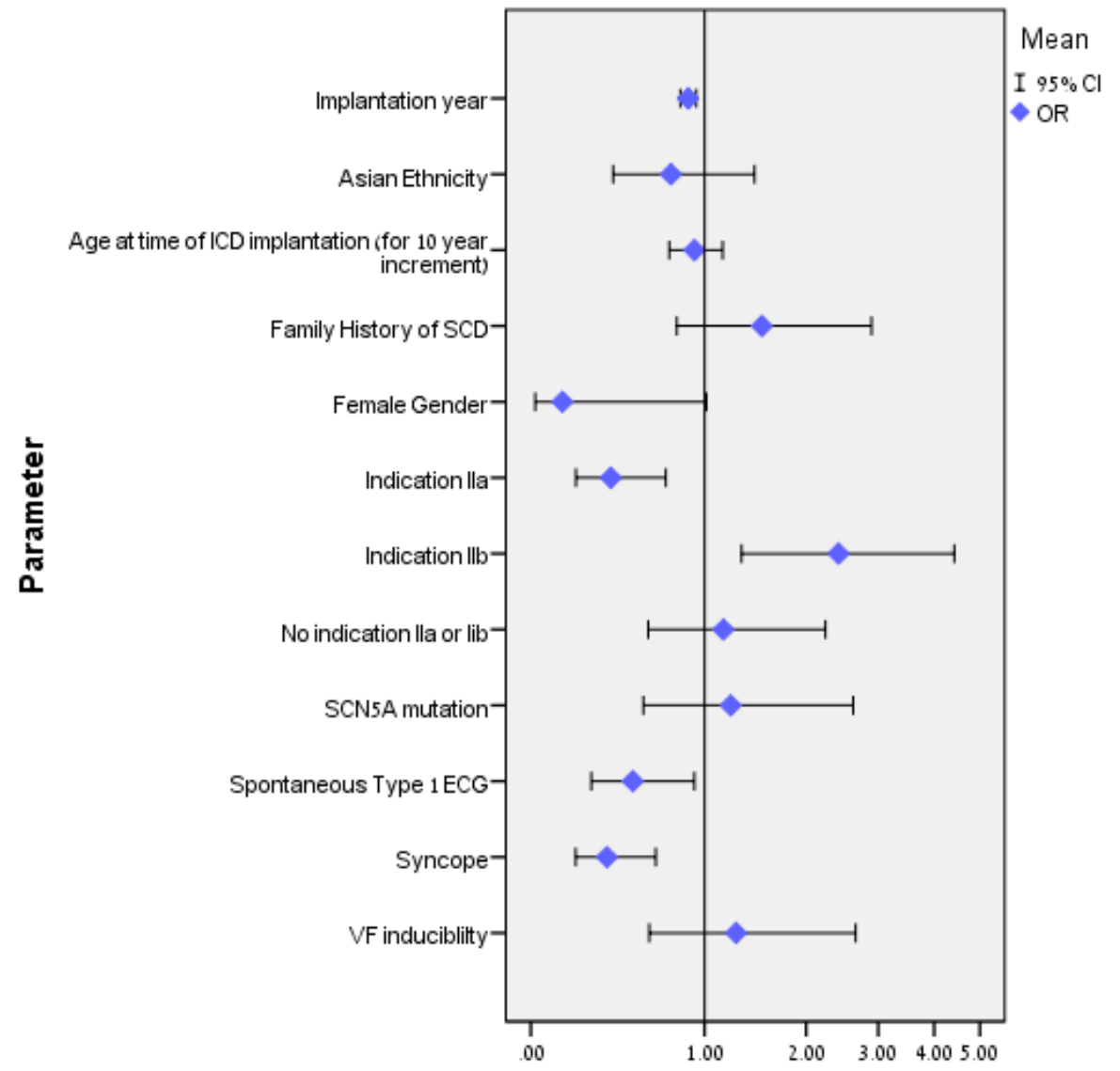


Figure 4. TScore - The Time-to-Shock Score (TScore). Panel A: This risk score sums the following risk factors found to have significance for an earlier AE after a prophylactic ICD implantation: One point is given for either prior syncope or the presence of a spontaneous type 1 Brugada-ECG. Panel B: A gender augmented score, using both the above risk factors and 2 points for female gender. P-value for trend between the score and the probability $<0.001$ for both scores.
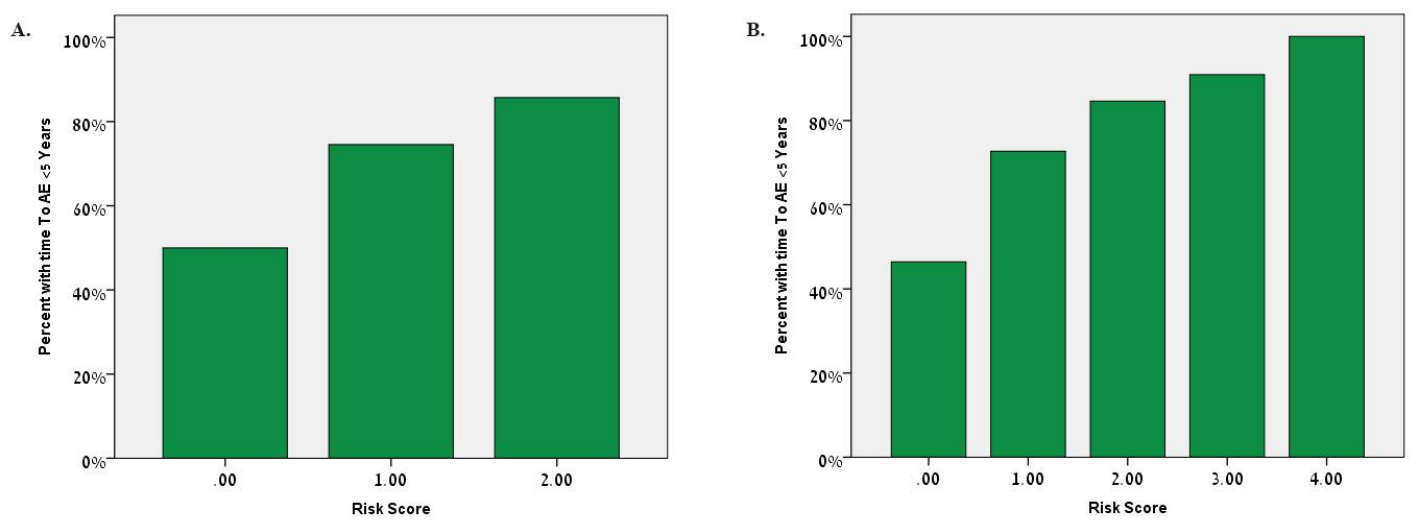


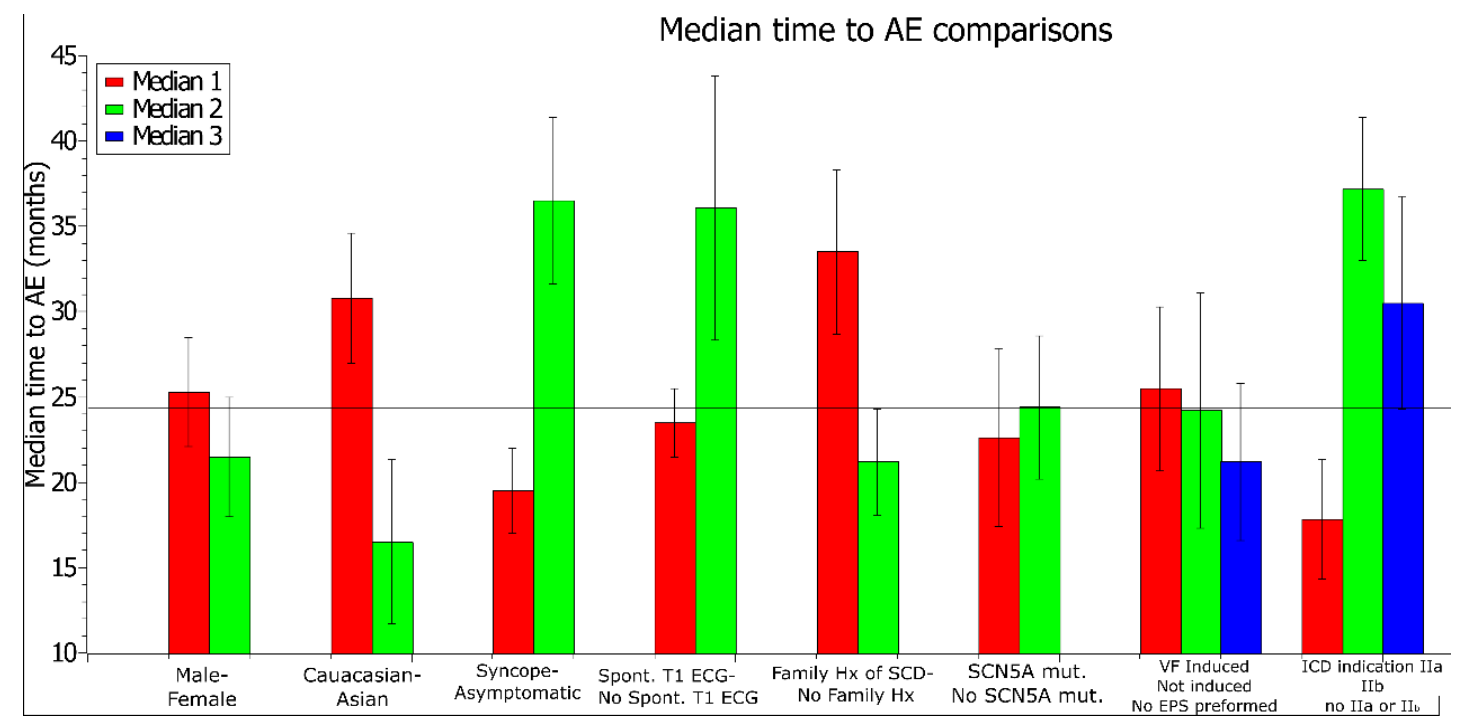

Median time-to-shock by different parameters. The median time-to-shock for the overall group was $24.4 \pm 2.8$ months. The figure displays the comparison of the median time-toshock by different patient characteristics: gender, ethnicity, symptoms, ECG type, family history of SCD, mutation, EPS results and ICD indication. (see text for elaboration). 
Click here to access/download

\section{Supplementary file \\ Supplemental.docx}

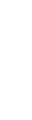
Supplementaldocx 